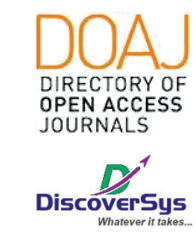

Published by DiscoverSys

\title{
Profil penderita Diabetes Mellitus Tipe-2 (DM-2) dengan komplikasi yang menjalani rawat inap di Rumah Sakit Umum Daerah (RSUD) Klungkung, Bali tahun 2018
}

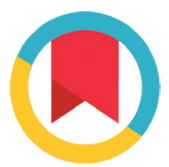

CrossMark

\author{
I Gede Restu Mahendra Sugiarta, ${ }^{1 *}$ I Gusti Ketut Darmita ${ }^{2}$
}

\section{ABSTRACT}

Background: DM is a metabolic disease with the characteristic of hyperglycemia due to insulin abnormality, insulin action, or a combination of insulin abnormality and insulin action. Klungkung accounted for the third-largest prevalence of DM after Jembrana and Buleleng with $1.6 \%$. Preliminary survey in Klungkung's Hospital 2019, shown that the number of patients with T2DM with a complication that hospitalized in 2018 were 253 people.

Method: This was a cross-sectional descriptive study aimed to determine the proportion of T2DM patient with complication and average Length of Stay (LOS) T2DM patient with complication. This study was carried out at the medical record installation of Klungkung's Hospital using secondary data obtained from medical record Klungkung's Hospital. Samples were all T2DM patients with the complication that hospitalized with 253 samples using a total sampling method. Data were processed and analyzed using the SPSS version 21 for Windows.

Result: The highest proportion of T2DM patient with complication based on age was 61 to 70 years old (36.0\%), based on sex was men (54.5\%), based on complication was diabetic foot (18.2\%), based on treatment was insulin (83.4\%), based on discharged from hospital was outpatient treatment $(90.5 \%)$, and based on source of cost was BPJS (94.9\%). The average LOS for patients T2DM with complication was 5.81 day.

Conclusion: Effort needed to reduce the prevalence of T2DM with complication and needed maximum services in the management of T2DM with complication to prevent further worsening patient's condition of T2DM with complication. One of them is giving strong education to patient regarding T2DM with complication.

Keywords: Profile, DMT2, Complication, Proportion, Klungkung

Cite this Article: Sugiarta, I.G.R.M., Darmita, I.G.K. 2020. Profil penderita Diabetes Mellitus Tipe-2 (DM-2) dengan komplikasi yang menjalani rawat inap di Rumah Sakit Umum Daerah (RSUD) Klungkung, Bali tahun 2018. Intisari Sains Medis 11(1): 7-12. D0I: 10.15562/ism.v11i1.515

ABSTRAK

Latar Belakang: DM merupakan penyakit metabolik dengan karakteristik berupa hiperglikemia akibat kelainan insulin, kerja insulin, atau kombinasi dari kelainan insulin dan kerja insulin. Klungkung menyumbang prevalensi DM terbesar ketiga setelah Jembrana dan Buleleng sebesar 1,6\%. Survei pendahuluan di RSUD

'Dokter Umum, Fakultas Kedokteran, Universitas Udayana, Bali, Indonesia

${ }^{2}$ SMF IImu Penyakit Dalam, Rumah Sakit Umum Daerah (RSUD) Klungkung, Bali, Indonesia

\section{"Korespondensi:}

I Gede Restu Mahendra Sugiarta; Dokter Umum, Fakultas Kedokteran, Universitas Udayana, Bali, Indonesia; dr.restumahendra@gmail.com

Diterima: 27-05-2019

Disetujui: 03-01-2020

Diterbitkan: 01-04-2020
Klungkung. Sampel adalah semua penderita DMT2 dengan komplikasi yang dirawat inap dengan jumlah 253 orang menggunakan metode total sampling. Data diolah dan dianalisis menggunakan program SPSS versi 21 untuk Windows.

Hasil: Proporsi penderita DMT2 dengan komplikasi tertinggi pada umur 61 s/d 70 tahun (36,0\%), jenis kelamin pada laki-laki (54,5\%), komplikasi pada diabetic foot $(18,2 \%)$, pengobatan pada insulin $(83,4 \%)$, keadaan sewaktu pulang pada berobat jalan $(90,5 \%)$, dan sumber biaya pada BPJS $(94,9 \%)$. Lama rawatan rata-rata penderita DMT2 dengan komplikasi adalah 5,81 hari.

Kesimpulan: Diperlukan suatu upaya untuk menurunkan angka kejadian DMT2 dengan komplikasi serta memaksimalkan pelayanan dalam penatalaksanaan DMT2 dengan komplikasi untuk mencegah perburukan komplikasi penderita yang lebih lanjut. Salah satunya berupa pemberian edukasi yang kuat kepada penderita mengenai DMT2 beserta komplikasi.
Kata Kunci: Profil, DMT2, Komplikasi, Proporsi, Klungkung.

Cite Pasal Ini: Sugiarta, I.G.R.M., Darmita, I.G.K. 2020. Profil penderita Diabetes Mellitus Tipe-2 (DM-2) dengan komplikasi yang menjalani rawat inap di Rumah Sakit Umum Daerah (RSUD) Klungkung, Bali tahun 2018. Intisari Sains Medis 11(1): 7-12. D0I: 10.15562/ism.v11i1.515 


\section{PENDAHULUAN}

Diabetes Mellitus (DM) merupakan kelompok penyakit metabolik dengan karakteristik meliputi hiperglikemia yang terjadi akibat kelainan insulin, kerja insulin, atau kombinasi dari kelainan insulin dan kerja insulin. ${ }^{1}$ Diabetes Mellitus Tipe 2 (DMT2) merupakan kasus yang sering ditemukan dan terhitung sekitar 90\% kasus dari semua DM yang ada di dunia. ${ }^{2}$ Laporan dari Centers for Disease Control and Prevention (CDC) 2017, menyebutkan sebanyak 30,3 juta penduduk di Amerika Serikat mengalami DM. ${ }^{3}$ Laporan dari International Diabetes Federation (IDF) 2017, memprediksi adanya kenaikan jumlah penderita DM di dunia dari 425 juta jiwa pada tahun 2017, menjadi 629 juta jiwa pada tahun 2045. Sedangkan di Asia Tenggara, dari 82 juta pada tahun 2017, menjadi 151 juta pada tahun 2045. Indonesia merupakan negara ke-7 dari 10 besar negara yang diperkirakan memiliki jumlah penderita DM sebesar 5,4 juta pada tahun 2045 serta memiliki angka kendali kadar gula darah yang rendah. ${ }^{4}$

Laporan hasil Riset Kesehatan Dasar (Riskesdas) Departemen Kesehatan Republik Indonesia (Depkes RI) 2013, menunjukkan bahwa rata-rata prevalensi DM di masing-masing provinsi Indonesia berdasarkan diagnosis dokter dari penduduk umur $\geq 15$ tahun pada tahun 2013 mencapai 1,5\%, dan meningkat pada tahun 2018 mencapai $2 \% .{ }^{5}$ Prevalensi terkecil terdapat di Nusa Tenggara Timur sebesar $0,9 \%$, sedangkan prevalensi terbesar terdapat di Daerah Khusus Ibukota (DKI) Jakarta sebesar 3,4\%. Prevalensi DM berdasarkan pemeriksaan darah dari penduduk umur $\geq 15$ tahun dengan konsensus Perkumpulan Endokrinologi Indonesia (Perkeni) 2011 pada tahun 2013 mencapai 6,9\%, dan meningkat pada tahun 2018 mencapai 8,5\%. Sedangkan prevalensi DM berdasarkan pemeriksaan darah dari penduduk umur $\geq 15$ tahun dengan konsensus Perkeni 2015 mencapai 10,9\% pada tahun $2018 .{ }^{5}$

Bali merupakan salah satu provinsi di Indonesia dengan kasus DM yang cukup banyak. Menurut laporan Riskesdas Depkes RI 2018, prevalensi DM di provinsi Bali berdasarkan diagnosis dokter dari penduduk umur $\geq 15$ tahun pada tahun 2013 mencapai 1,5\%, dan meningkat pada tahun 2018 mencapai $1,8 \% .{ }^{4}$ Menurut laporan penelitian sebelumnya yang dilakukan tahun 2010 menunjukkan bahwa prevalensi terkecil DM berdasarkan diagnosis atau gejala yang ditimbulkan pada penduduk umur $\geq 15$ tahun terdapat di Karangasem dan Gianyar sebesar 1,0\%, sedangkan prevalensi terbesar terdapat di Jembrana sebesar 2,0\%. Klungkung menyumbang prevalensi DM terbesar ketiga setelah Jembrana dan Buleleng sebesar 1,6\%. ${ }^{6}$
Rumah Sakit Umum Daerah (RSUD) Klungkung merupakan salah satu rumah sakit utama tipe B milik pemerintah kabupaten Klungkung yang terletak di kota Klungkung. Berdasarkan hasil survei pendahuluan di RSUD Klungkung tahun 2019, jumlah penderita DMT2 beserta komplikasi yang dirawat inap di RSUD Klungkung pada tahun 2018 sebanyak 253 orang. Berkaitan dengan hal tersebut maka penelitian ini bertujuan untuk mengetahui profil penderita DMT2 dengan komplikasi yang dirawat inap di RSUD Klungkung pada tahun 2018.

\section{METODE}

Penelitian ini merupakan penelitian deskriptif dengan metode potong lintang (cross-sectional) yang bertujuan untuk mengetahui profil penderita DMT2 dengan komplikasi yang dirawat inap di RSUD Klungkung pada tahun 2018. Profil penderita yang diteliti ada 2 bagian, yaitu proporsi penderita DMT2 dengan komplikasi (berdasarkan umur penderita, jenis kelamin, komplikasi yang dialami, pengobatan selama perawatan di rumah sakit, keadaan sewaktu pulang, sumber biaya yang digunakan), dan lama rawatan rata-rata penderita DMT2 dengan komplikasi yang dirawat inap di RSUD Klungkung.

Penelitian ini dilaksanakan di ruang instalasi rekam medis RSUD Klungkung dengan pertimbangan tersedianya data rekam medis yang lengkap mengenai penderita yang dirawat inap dengan diagnosis DMT2 beserta komplikasi pada tahun 2018. Data yang digunakan adalah data sekunder yang diperoleh dari catatan rekam medis penderita DMT2 dengan komplikasi yang dirawat inap di RSUD Klungkung. Jenis data yang digunakan adalah data kuantitatif. Populasi dan sampel pada penelitian ini adalah semua penderita DMT2 dengan komplikasi yang dirawat inap di bangsal Cermai, Jambu, dan Kedondong RSUD Klungkung. Jumlah sampel pada penelitian ini berjumlah 253 orang dengan metode total sampling yang didapat dari hasil survei pendahuluan di RSUD Klungkung tahun 2019.

Keseluruhan data dikumpulkan dan dicatat di program Microsoft Office Excel 2010, kemudian diolah dan dianalisis secara statistik menggunakan program SPSS versi 21 untuk Windows untuk ditampilkan dalam bentuk persentasi, jumlah, rerata, maupun simpang baku dan interval kepercayaan.

\section{HASIL}

Hasil pada Tabel 1 menunjukkan bahwa proporsi profil penderita DMT2 dengan komplikasi yang dirawat inap di RSUD Klungkung dapat dijabarkan 
Tabel 1 Karakteristik penderita DMT2 dengan komplikasi yang dirawat inap di RSUD Klungkung tahun 2018

\begin{tabular}{|c|c|c|}
\hline Parameter & & Jumlah (\%) \\
\hline \multirow[t]{7}{*}{ Umur Penderita } & $21 \mathrm{~s} / \mathrm{d} 30$ tahun & $1(0,4)$ \\
\hline & $31 \mathrm{~s} / \mathrm{d} 40$ tahun & $9(3,6)$ \\
\hline & $41 \mathrm{~s} / \mathrm{d} 50$ tahun & $30(11,9)$ \\
\hline & $51 \mathrm{~s} / \mathrm{d} 60$ tahun & $75(29,6)$ \\
\hline & $61 \mathrm{~s} / \mathrm{d} 70$ tahun & $91(36,0)$ \\
\hline & $71 \mathrm{~s} / \mathrm{d} 80$ tahun & $43(17,0)$ \\
\hline & 80 tahun ke atas & $4(1,6)$ \\
\hline \multirow[t]{2}{*}{ Jenis Kelamin } & Laki-laki & $138(54,5)$ \\
\hline & Perempuan & $115(45,5)$ \\
\hline \multirow[t]{15}{*}{ Komplikasi } & Hipoglikemia & $36(14,2)$ \\
\hline & Hiperglikemia akut & $38(15,0)$ \\
\hline & Diabetic foot & $46(18,2)$ \\
\hline & Pneumonia & $20(7,9)$ \\
\hline & Stroke & $28(11,1)$ \\
\hline & Penyakit jantung koroner & $20(7,9)$ \\
\hline & Hipertensi & $8(3,2)$ \\
\hline & Diabetic nefropathy & $13(5,1)$ \\
\hline & Diabetic neuropathy & $1(0,4)$ \\
\hline & Diabetic gastropathy & $17(6,7)$ \\
\hline & Tuberkulosis paru & $3(1,2)$ \\
\hline & Infeksi saluran kemih & $10(4,0)$ \\
\hline & Peripheral arterial disease & $3(1,2)$ \\
\hline & Anemia & $7(2,8)$ \\
\hline & Vertigo & $3(1,2)$ \\
\hline \multirow[t]{3}{*}{ Pengobatan } & $\mathrm{OHO}$ & $29(11,5)$ \\
\hline & Insulin & $211(83,4)$ \\
\hline & Kombinasi (OHO dan Insulin) & $13(5,1)$ \\
\hline \multirow[t]{3}{*}{ Keadaan Sewaktu Pulang } & Berobat jalan & $229(90,5)$ \\
\hline & Dirujuk ke RS lain & $3(1,2)$ \\
\hline & Pulang Paksa & $3(1,2)$ \\
\hline \multirow[t]{3}{*}{ Sumber Biaya } & Meninggal & $18(7,1)$ \\
\hline & BPJS & $240(94,9)$ \\
\hline & Umum & $13(5,1)$ \\
\hline
\end{tabular}

Tabel 2 Rata-rata rawat inap penderita DMT2 dengan komplikasi yang dirawat inap di RSUD Klungkung tahun 2018

\begin{tabular}{cccc}
\hline $\begin{array}{c}\text { Rata-Rata Rawat } \\
\text { Inap (Hari) }\end{array}$ & $\begin{array}{c}\text { Median } \\
\text { (Minimum-Maksimum) }\end{array}$ & $\begin{array}{c}\text { Simpang } \\
\text { Baku (SB) }\end{array}$ & 95\% IK \\
\hline 5,81 & $5(1-21)$ & 3,81 & $5,34-6,28$ \\
\hline
\end{tabular}

dalam beberapa kategori. Proporsi berdasarkan umur lebih tinggi pada umur 61-70 tahun sebesar $36,0 \%$, dan lebih rendah pada umur 21-30 tahun sebesar $0,4 \%$. Proporsi berdasarkan jenis kelamin lebih tinggi pada laki-laki sebesar 54,5\%, sedangkan perempuan sebesar 45,5\%. Proporsi berdasarkan komplikasi lebih tinggi pada diabetic foot sebesar $18,2 \%$. dan lebih rendah pada diabetic neuropathy sebesar 0,4\% (Tabel 1). Proporsi berdasarkan pengobatan lebih tinggi pada insulin sebesar 83,4\%, kemudian Obat Hiperglikemik Oral (OHO) sebesar 11,5\%, dan kombinasi (OHO dan insulin) sebesar 5,1\% (Tabel 1). Proporsi berdasarkan keadaan sewaktu pulang lebih tinggi pada berobat jalan sebesar 90,5\%, kemudian meninggal sebesar 7,1\%, serta dengan dirujuk ke RS lain dan dengan pulang paksa sebesar $1,2 \%$. Proporsi berdasarkan sumber biaya lebih tinggi pada BPJS sebesar 90,5\%, sedangkan umum sebesar 7,1\% (Tabel 1).

Dari Tabel 2, dapat dilihat bahwa lama rawatan rata-rata penderita DMT2 dengan komplikasi yang dirawat inap di RSUD Klungkung adalah 5,81 hari. Kemudian simpang baku (SB) pada penelitian ini adalah 3,81 hari, lama rawatan minimal 1 hari, nilai median 5 hari, dan lama rawatan maksimal 29 hari. Dari 95\% Interval Kepercayaan (IK) dapat dilihat bahwa 95\% diyakini lama rawatan rata-rata penderita DMT2 dengan komplikasi yang dirawat inap di RSUD Klungkung berkisar antara 5,34 s/d 6,28 hari (Tabel 2).

\section{PEMBAHASAN}

Proporsi penderita DMT2 dengan komplikasi yang dirawat inap di RSUD Klungkung tahun 2018 berdasarkan umur lebih tinggi pada umur $61 \mathrm{~s} / \mathrm{d} 70$ tahun sebesar $36,0 \%$. Hal ini sesuai dengan penelitian oleh Nainggolan (2017), yang menyatakan bahwa proporsi penderita DMT2 dengan komplikasi yang dirawat inap di RSUP $\mathrm{H}$. Adam Malik Medan lebih tinggi pada umur $>40$ tahun sebesar 94,0\% (dengan jumlah sampel sebesar 150 orang yang terhitung dari tahun 2016). ${ }^{7}$

Umur merupakan salah satu faktor risiko terjadinya DMT2. DMT2 terjadi pada umur tua meskipun bisa terjadi pada umur dewasa tua maupun umur dewasa muda. Menurut data Riskesdas RI 2018, prevalensi DM di Indonesia menurut karakteristik berdasarkan umur lebih tinggi didapatkan pada umur $55 \mathrm{~s} / \mathrm{d} 64$ tahun dan umur $65 \mathrm{~s} / \mathrm{d} 74$ tahun sebesar 19,6\%, diikuti dengan umur 75 tahun keatas sebesar 17,9\%, dan umur 45 s/d 54 tahun sebesar $14,4 \% .{ }^{5}$ Kelompok umur dewasa tua maupun umur tua merupakan kelompok yang paling sering terjadinya kasus DMT2. ${ }^{8} \mathrm{Hal}$ ini disebabkan oleh karena kemampuan insulin yang semakin berkurang akibat resistensi insulin atau produksi insulin oleh sel beta pankreas yang semakin menurun seiring terjadinya ageing process yang semakin berlanjut dalam tubuh umur dewasa tua maupun umur tua. ${ }^{9,10}$

Proporsi penderita DMT2 dengan komplikasi yang dirawat inap di RSUD Klungkung tahun 2018 
berdasarkan jenis kelamin lebih tinggi pada lakilaki sebesar 54,5\%, sedangkan perempuan sebesar $45,5 \%$. Hal ini tidak sesuai dengan hasil penelitian oleh Nainggolan tahun 2017 yang menyatakan bahwa proporsi penderita DMT2 dengan komplikasi yang dirawat inap di RSUP H. Adam Malik Medan berdasarkan jenis kelamin lebih tinggi pada perempuan sebesar 51,3\%, sedangkan laki-laki sebesar $48,7 \%{ }^{7}$

Proporsi penderita DMT2 dengan komplikasi yang dirawat inap di RSUD Klungkung tahun 2018 dengan laki-laki lebih besar dibandingkan perempuan, disebabkan oleh karena laki-laki lebih sering datang ke RSUD Klungkung dengan komplikasi yang lebih serius dibandingkan perempuan. Namun, menurut Powers tahun 2012 laki-laki maupun perempuan memiliki prevalensi DM yang sama dalam semua umur di berbagai negara dunia. ${ }^{11}$ Dengan demikian, baik laki-laki maupun perempuan memiliki proporsi yang sama tinggi menderita DMT2 baik tanpa komplikasi maupun dengan komplikasi.

Pada penelitian ini, proporsi penderita DMT2 dengan komplikasi yang dirawat inap di RSUD Klungkung berdasarkan komplikasi lebih tinggi pada diabetic foot sebesar 18,2\%. Hal ini sesuai dengan hasil penelitian oleh Nainggolan (2017), yang menyatakan bahwa proporsi penderita DMT2 dengan komplikasi yang dirawat inap di RSUP $\mathrm{H}$. Adam Malik Medan berdasarkan komplikasi lebih tinggi pada diabetic foot sebesar 38,0\%.7

DMT2 lebih dahulu terjadi sebelum terjadinya kerusakan di beberapa organ yang menimbulkan berbagai macam komplikasi. Hal ini disebabkan oleh karena DMT2 merupakan faktor pencetus timbulnya berbagai macam komplikasi penyakit jika tidak ditanggulangi dengan segera. ${ }^{12}$ Di samping itu, DMT2 disebut juga sebagai silent killer oleh karena pada awalnya tidak menimbulkan gejala. ${ }^{12}$ Dalam hal ini, diabetic foot lebih banyak didapatkan pada penderita DMT2 dengan komplikasi yang dirawat inap di rumah sakit kemungkinan disebabkan oleh karena beberapa faktor, antara lain karena kasus DMT2 dengan penyulit diabetic foot merupakan kasus yang cukup banyak ditemukan di rumah sakit atau penderita DMT2 dengan penyulit diabetic foot memiliki tingkat kepatuhan dalam pengobatan dan pengelolaan DMT2 yang kurang.

Proporsi penderita DMT2 dengan komplikasi yang dirawat inap di RSUD Klungkung tahun 2018 berdasarkan pengobatan lebih tinggi pada insulin sebesar $83,4 \%$, diikuti OHO sebesar $11,5 \%$, dan kombinasi $\mathrm{OHO}$ dan insulin sebesar 5,1\%. Hal ini sesuai dengan hasil penelitian oleh Nainggolan menyatakan bahwa proporsi penderita DMT2 dengan komplikasi yang dirawat inap di RSUP $\mathrm{H}$. Adam Malik Medan berdasarkan pengobatan lebih tinggi pada insulin sebesar 54,7\%, diikuti $\mathrm{OHO}$ sebesar $31,3 \%$, dan kombinasi OHO dan insulin sebesar $14,0 \%{ }^{7}$

Penggunaan terapi insulin diperlukan bila terdapat keadaan sebagai berikut : kadar $\mathrm{HbAlc}$ $>$ 9,0\% dengan kondisi dekompensasi metabolik, kondisi hiperglikemia berat dengan ketosis maupun non-ketosis, adanya infeksi sistemik, DM dengan gangguan fungsi ginjal dan hati, infark miokard akut, stroke, DM dengan kehamilan, gagal dengan terapi OHO dosis optimal, serta kondisi perioperatif yang sesuai dengan indikasi pemberian insulin. ${ }^{1}$ Pada penelitian ini, sebanyak $83,4 \%$ penderita DMT2 dengan komplikasi menggunakan insulin sebagai terapi untuk DMT2 oleh karena insulin sangat dianjurkan pada pasien DMT2 dengan berbagai keadaan khusus terutama hampir semua kasus komplikasi yang dialaminya. Akan tetapi, didapatkan juga penggunaan $\mathrm{OHO}$ maupun kombinasi sebagai terapi untuk DMT2 dengan komplikasi tergantung dari clinical judgement dokter yang menangani penderita DMT2 dengan komplikasi.

Proporsi penderita DMT2 dengan komplikasi yang dirawat inap di RSUD Klungkung tahun 2018 berdasarkan keadaan sewaktu pulang lebih tinggi berobat jalan sebesar 90,5\%, diikuti meninggal sebesar 7,1\%, serta dirujuk ke RS lain dan pulang paksa sebesar 1,2\%. Hal ini sesuai dengan hasil penelitian oleh Nainggolan yang menyatakan bahwa proporsi penderita DMT2 dengan komplikasi yang dirawat inap di RSUP H. Adam Malik Medan berdasarkan keadaan sewaktu pulang lebih tinggi pulang berobat jalan sebesar $68,7 \%$, sedangkan yang meninggal sebesar 22,0\%. ${ }^{7}$

Berdasarkan hal ini, dapat terlihat bahwa banyaknya penderita DMT2 dengan komplikasi dengan pulang berobat jalan kemungkinan disebabkan oleh beberapa faktor, seperti pelayanan kesehatan yang sudah baik dalam menangani penderita DMT2 dengan komplikasi, serta keadaan klinis penderita yang sudah membaik setelah pemberian terapi selama menjalani perawatan di rumah sakit. Sedangkan penderita yang meninggal, disebabkan oleh karena saat datang sudah dalam keadaan prognosis buruk sehingga kondisi klinis penderita DMT2 dengan komplikasi yang dialami tidak membaik setelah pemberian terapi oleh dokter yang menangani penderita bersangkutan. Ada beberapa penyebab komplikasi serius yang dapat menimbulkan kematian pada penderita DMT2 dengan komplikasi. Menurut Zheng komplikasi kardiovaskular merupakan penyebab utama morbiditas dan mortalitas penderita DMT2 dengan 
komplikasi. ${ }^{8}$ Sedangkan menurut penelitian oleh Ojobi komplikasi krisis hiperglikemia merupakan penyebab utama kematian DMT2 dengan komplikasi. $^{13}$

Proporsi penderita DMT2 dengan komplikasi yang dirawat inap di RSUD Klungkung tahun 2018 berdasarkan sumber biaya lebih tinggi pada BPJS sebesar $94,9 \%$, sedangkan dengan umum sebesar $5,1 \%$. Hal ini sesuai dengan hasil penelitian oleh Nainggolan menyatakan bahwa proporsi penderita DMT2 dengan komplikasi yang dirawat inap di RSUP H. Adam Malik Medan berdasarkan sumber biaya lebih tinggi pada BPJS sebesar 91,3\%, sedangkan yang umum sebesar $8,7 \%{ }^{7}$

Lama rawatan rata-rata penderita DMT2 dengan komplikasi yang dirawat inap di RSUD Klungkung tahun 2018 adalah 5,81 hari dengan lama rawatan terendah selama 1 hari dan lama rawatan tertinggi selama 21 hari. Hal ini tidak sesuai dengan hasil penelitian yang dilakukan oleh Nainggolan yang menyatakan bahwa lama rawatan rata-rata penderita DMT2 dengan komplikasi yang dirawat inap di RSUP H. Adam Malik Medan adalah 10 hari dengan lama rawatan terendah selama 1 hari dan tertinggi selama 32 hari. ${ }^{7}$ Di samping itu, menurut penelitian oleh Chen (2017) di China, lama rawatan penderita DMT2 baik tanpa komplikasi maupun dengan komplikasi yang dirawat inap di Zhongnan Hospital negara China adalah 11,65 hari. ${ }^{14}$ Lama rawat yang rendah mengindikasikan bahwa penderita dalam waktu yang singkat sudah bisa pulang berobat jalan dalam keadaan membaik atau justru meninggal di rumah sakit akibat komplikasi yang berat dialami oleh penderita, sedangkan lama rawat yang tinggi mengindikasikan bahwa penderita memerlukan perawatan yang intensif atau dalam waktu yang lama menjalani masa perawatan di bangsal rumah sakit. Dengan demikian, lama rawatan rata-rata penderita DMT2 dengan komplikasi di masing-masing daerah berbeda.

\section{SIMPULAN}

Proporsi penderita DMT2 dengan komplikasi yang dirawat inap di RSUD Klungkung tertinggi pada umur $61 \mathrm{~s} / \mathrm{d} 70$ tahun, jenis kelamin pada laki-laki, komplikasi dengan diabetic foot, pengobatan dengan insulin, keadaan sewaktu pulang dengan pulang berobat jalan, dan lama rawat ratarata selama 5,81 hari. Dalam hal ini, diperlukan suatu upaya untuk menurunkan angka kejadian DMT2 dengan komplikasi serta memaksimalkan pelayanan dalam penatalaksanaan DMT2 dengan komplikasi untuk mencegah perburukan kondisi yang lebih lanjut. Salah satunya berupa pemberian edukasi yang kuat kepada penderita mengenai DMT2 beserta komplikasi.

\section{KONFLIK KEPENTINGAN}

Tidak terdapat konflik kepentingan dalam penulisan laporan penelitian ini.

\section{ETIKA PENELITIAN}

Penelitian ini telah mendapat persetujuan etik dari Komisi Etik Rumah Sakit Umum Daerah (RSUD) Klungkung, Bali, Indonesia sebelum penelitian berjalan.

\section{PENDANAAN}

Penulis bertanggung jawab terhadap pendanaan penelitian ini.

\section{KONTRIBUSI PENULIS}

Semua penulis memiliki kontribusi yang sama dalam penulisan laporan penelitian ini baik dari tahap pembentukan kerangka berpikir, pengumpulan data, analisis data penelitian, hingga pelaporan hasil penelitian.

\section{DAFTAR PUSTAKA}

1. Soelistijo SA, Novida H, Rudijanto A, Soewondo P, Suastika K, Manaf A, et al. Konsensus Pengelolaan dan Pencegahan Diabetes Mellitus Tipe 2 di Indonesia 2015. Jakarta: PB PERKENI; 2015:1-93

2. Kalyani RR, Golden SH, Cefalu WT. Diabetes and Aging: Unique Considerations and Goals of Care. Diabetes Care. 2017;40(4):440-443.

3. Gao HX, Regier EE, Close KL. Prevalence of and trends in diabetes among adults in the United States, 1988-2012. J Diabetes. 2016;8(1):8-9.

4. Artha IMJR, Bhargah A, Dharmawan NK, Pande UW, Triyana KA, Mahariski PA, et al. High level of individual lipid profile and lipid ratio as a predictive marker of poor glycemic control in type- 2 diabetes mellitus. Vasc Health Risk Manag. 2019;15:149-157.

5. Ligita T, Wicking K, Francis K, Harvey N, Nurjannah I. How people living with diabetes in Indonesia learn about their disease: A grounded theory study. PLoS One. 2019;14(2):e0212019.

6. Suastika K, Dwipayana P, Saraswati IMR, Gotera W, Budhiarta AAG, Sutanegara IND, et al. An epidemiological study on obesity, glucose intolerance and metabolic syndrome in population of Bali, Indonesia. Diabetes. 2010;59(Suppl 1): A608

7. Nainggolan SY, Hiswani, Lubis SN. Karakteristik Penderita Diabetes Mellitus Tipe 2 dengan Komplikasi yang Dirawat Inap di Rumah Sakit Umum Pusat Haji Adam Malik Medan Tahun 2016. Jurnal Gizi, Kesehatan Reproduksi, dan Epidemiologi. 2017;1(2):1-10.

8. Zheng Y, Ley SH, Hu FB. Global Aetiology and Epidemiology of Type 2 Diabetes Mellitus and Its Complications. Nat Rev Endocrinol. 2018;14(2):88-98

9. Kurniawaty E, Yanita B. Faktor-faktor yang Berhubungan dengan kejadian Diabetes Mellitus Tipe 2. Majority. 2016;5(2):27-31.

10. Suastika K, Dwipayana P, Semadi MS, Kuswardhani RAT. Age is an Important Risk Factor for Type 2 Diabetes Mellitus and Cardiovascular Diseases. Glucose Tolerance: Intech Open. 2012:67-76 
11. Powers AC. Diabetes Mellitus. In Longo DL, Kasper DL, Jameson JL, Fauci AS, Hauser SL, Loscalzo J. Harrison's Principle of Internal Medicine. 18 Rev. Ed USA: McGrawHill; 2012:2968-3002.

12. Todkar SS. Diabetes Mellitus the "Silent Killer" of Mankind: An Overview on the Eve up Upcoming World Health Day. J Med Allied Sci. 2016;6(1):39-44

13. Ojobi JE, Odoh G, Aniekwensi E, Dunge J. Mortality among Type 2 Diabetic in-patients in a Nigerian Tertiary Hospital. African Journal of Diabetes Medicine. 2016;24(2):17-19.
14. Chen D, Liu S, Tan X, Zhao Q. Assessment of Hospital Length of Stay and Direct Costs of Type 2 Diabetes in Hubei Province China. BMC Health Serv Res. 2017;17(1):199.

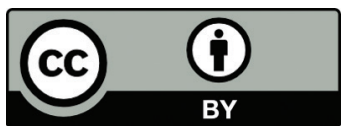

This work is licensed under a Creative Commons Attribution 